Jurnal Adat dan Budaya, Vol.2, No.2 Tahun 2020

ISSN: E-ISSN 2615-6156, P-ISSN: 2615-6113

Jurnal Homepage: https://ejournal.undiksha.ac.id/index.php/JABI/index

\title{
MODEL PEMBELAJARAN ROUND CLUB BERBASIS TRI KAYA PARISUDHA TERHADAP KOMPETENSI PENGETAHUAN PPKn
}

\author{
Ni Luh Dian'1, I.G.A Agung Sri Asri2, I Ketut Ardana ${ }^{3}$ \\ 123Program Studi Pendidikan Guru Sekolah Dasar, Universitas Pendidikan Ganesha, Bali, Indonesia \\ E-mail: luh.dian@undiksha.ac.id
}

\begin{abstract}
Abstrak
Penelitian ini dilatarbelakangi oleh rendahnya kompetensi pengetahuan PPKn siswa kelas IV di SDN Gugus III Kecamatan Tampaksiring Tahun Ajaran 2019/2020.Penelitian ini bertujuan untuk menganalisis apakah terdapat pengaruh model pembelajaran Round Club berbasis Tri Kaya Parisudha terhadap kompetensi pengetahuan PPKn siswa kelas IV SDN Gugus III Kecamatan Tampaksiring Tahun Ajaran 2019/2020. Jenis penelitian ini adalah eksperimen semu dengan menggunakan rancangan nonequivalent control group design. Populasi penelitian ini adalah seluruh kelas IV SDN Gugus III Kecamatan Tampaksiring terdiri dari 5 kelas dengan jumlah populasi sebanyak 149 siswa dari 5 Sekolah Dasar. Sampel penelitian ini berjumlah 64 orang siswa yaitu 33 siswa kelas IV SD Negeri 2 Sanding yang menjadi kelompok eksperimen dan 31 orang siswa kelas IV SD Negeri 1 Pejeng Kaja yang menjadi kelompok kontrol Penentuan sampel dalam penelitian ini menggunakan teknik random sampling. Metode pengumpulan data dalam penelitian ini yaitu metode tes, instrumen tes pilihan ganda biasa. Data posttest kompetensi pengetahuan PPKn dianalisis menggunakan uji-t dengan rumus polled varians Data yang diperoleh $t_{\text {hitung }}=3,267$ dan pada taraf signifikansi 5\% dan $\mathrm{dk}=\mathrm{n}_{1}+\mathrm{n}_{2}-2=62$ maka diperoleh nilai tabel $=2,000$. , Sehingga $t_{\text {hitung }}>\mathrm{t}_{\text {tabel, }} \mathrm{H}_{0}$ ditolak dan $\mathrm{H}_{\mathrm{a}}$ diterima. Nilai rata-rata kompetensi pengetahuan PPKn siswa kelompok eksperimen $\bar{X}=86,76>$ kelompok kontrol $\bar{X}=80,16$. Dengan demikian dapat disimpulkan bahwa model pembelajaran Round Club berbasis Tri Kaya Parisudha berpengaruh terhadap kompetensi pengetahuan PPKn siswa kelas IV SDN Gugus III Kecamatan Tampaksiring tahun ajaran 2019/2020.
\end{abstract}

Kata Kunci: Round Club; Tri Kaya Parisudha; Kompetensi Pengetahuan PPkn.

\begin{abstract}
This research is motivated by the low level of knowledge competence of PPKn students in class IV SDN Gugus III Tampaksiring Sub district of Academic Year 2019 / 2020. . The purpose of this study was to determine the effect of the Round Club model on Tri Kaya Parisudha toward the knowledge competence of PPKn among the $4^{\text {th }}$ grade students of SDN Gugus III Tampaksiring Sub district of Academic Year 2019/2020. A quasi-experimental study was used with Nonequivalent Control Group Design. The population of this research is the whole class IV SDN Gugus III Tampaksiring Sub district consists of 5 classes with a population of 149 students from 5 elementary schools. The sample of this research was 64 students, 33 students in class IV SD Negeri 2 Sanding who were in the experimental group and 31 students in class IV SD Negeri 1 Pejeng Kaja who were in the control group. Determination of the sample in this study was using random sampling techniques. Data collection methods in this research are test method, ordinary multiple choice test instrument. Posttest data of PPKn knowledge competence were analyzed using t-test with polled variance formula. The results of the $t_{\text {count }}=3.267$ and and $t_{\text {table }}$ at $a$ significance level of $5 \%$ with df $62=2.000$. Therefore, $t_{\text {count }}>t_{\text {table, }} H_{0}$ was rejected and $H_{a}$ was accepted. The average value of PPKn knowledge competence of students in the experimental group $\bar{X}=86.76>$ the control group $\bar{X}=80.16$. The conclusion is the round Club model on Tri Kaya Parisudha influences the knowledge competence of PPKn among the $4^{\text {th }}$ grade students of SDN Gugus III Tampaksiring Sub district of Academic Year 2019/2020.
\end{abstract}

Keywords: Round Club; Tri Kaya Parisudha; PPKn Knowledge Competence 


\section{PENDAHULUAN}

Upaya untuk mewujudkan sumber daya manusia yang berkualitas dan mutu pendidikan diperlukan proses pembelajaran yang optimal agar dapat mencapapai kompetensi. Suatu pendidikan yang memiliki kualitas akan sangat berpengaruh terhadap kemajuan dalam berbagai bidang. Berdasarkan UU No. 20 tahun 2003 mengenai sistem pendidikan nasional dalam pasal 1 butir 1 berbunyi pendidikan adalah suatu kegiatan yang sudah ada rencana menciptakan kegiatan belajar mengajar agar siswa mampu aktif dan kreatif dalam meningkatkan kemampuan diri agar memunyai rasa spiritual, kecakapan diri, kepribadian, memiliki pengetahuan, berakhlak, dan peningkatan keterampilan.Menurut Daryanto (2014)sekolah memiliki peran yang amat sangat penting dalam meningkatkan sumber daya manusia melalui pencapaian mutu pendidikan. Untuk mencapai hal tersebut maka dilakukan pembaharuan dalam model, metode, dan strategi pembelajaran agar tercipta proses pembelajaran yang berkualitas sesuai dengan Kurikulum 2013 di masa sekarang. Salah satu upaya untuk meningkatkan kualitas pendidikan tersebut yaitu melalui pembelajaran dengan berlandaskan dasar berperilaku yang baik dalam proses pembelajaran, sehingga pembelajaran dapat berjalan dengan baik.(Bachtiar et al., 2019)

Pembelajaran PPKn adalah suatu muatan pembelajaran yang penting di sekolah dasar guna menciptakan peserta didik menjadi manusia yang mempunyai rasa kebangsaan yang tinggi dan cinta tanah air. Menurut Kosasih (2016) kompetensi merupakan suatu ilmu yang berkaitan dengan pengetahuan, adanya sikap terampil, dan suatu nilai yang dijadikan dasar untuk merefleksikan dalam suatu hal kebiasaan, dalam berpikir dan melakukan tindakan. Pembelajaran berbasis kompetensi mengutamakan penciptaan dan peningkatan dari kecerdasan yang dimiliki oleh siswa, agar dikehidupan mendatang mereka bisa mengatasi tantangan. Menurut Darmad (2015) PPKn berpengaruh penting dalam meningkatkan tujan berbangsa. Menurut Yuliasari (2013) Adapun tujuan utama PPKn adalah meningkatkan wawasan peserta didik dan rasa cinta tanah air yang berdedikasi tinggi. Menurut Astiti (2017) PPKn memiliki ikatan dan berjalan beriringan dengan perjalanan pembangunan kehidupan berbangsa dan bernegara. Di sekolah dasar muatan pelajaran PPKn diharapkan agarsiswa sejak dini mampu memahami melaksanakan hak-hak dan kewajibannya menjadi warga negara Indonesia yang mempunyai sikap cerdas dan berkarakter sesuai Pancasila dan UUD 1945 (Septiari, 2019). Melalui muatan pelajaran PPKn di sekolah dasar peserta mampu mempunyai wawasan mengenai pendidikan yang demokrasi dan kesadaran terhadap adanya masalah sosial di lingkungan sekitarnya. Menurut Dharma (2018) kehadiran kurikulum PPKn dimaksudkan agar manusia bisa menumbuhkembangkan sikap yang lebih baik kepada warga negara dan para generasi muda bangsa agar mampu mempunyai wawasan yang luas, serta rasa cinta tanah air sebagai pencapaian seorang warga negara mempunyai rasa bertanggungjawab atas kelangsungan hidup bangsa dan negara yang ditanamkan konsep dari UUD 1945, Bhineka Tunggal Ika, Pancasila dan NKRI. Menurut Puspitasari (2013) PPKn mempunyai peran yang dikatakan strategis dalam mempersiapkan warga yang memiliki sikap cerdas serta berkeadaban.

Berdasarkan hasil observasi pada siswa kelas IV di SDN Gugus III Kecamatan Tampaksiring tahun ajaran 2019/2020 terdiri dari 5 sekolah yaitu SDN 1 Sanding, SDN 2 Sanding, SDN 1 Pejeng Kaja, SDN 2 Pejeng Kaja dan SDN 3 Pejeng Kaja. Jumlah siswa kelas 4 di gugus III Kecamatan Tampaksiring adalah 149 siswa. Dari ke 5 (lima) Sekolah Dasar Negeri tersebut dalam proses pembelajaran tematik khususnya pembelajaran bermuatan PPKn siswa kelas IV di SDN Gugus III Kecamatan Tampaksiring tahun pelajaran 2019/2020 banyak peserta didik yang masih kurang dalam berpartisipasi aktif dikelas saat pembelajaran berlangsung, siswa kurang disiplin dan bertanggung jawab saat mengikuti pembelajran. Khususnya dalam pembelajaran tematik bermuatan PPKn, siswa sulit memahai materi yang di belajarkan, proses belajar kurang bermakna bagi siswa sehingga konsep yang diperoleh belum dapat diaplikasikan dalam kehidupannya sehari-hari dengan tepat dan kompetensi pengetahuan siswa yang diperoleh sebagian besar masih rendah terlihat dari 45 siswa atau 32\% masih belum mencapai KKM. Menurut (Murni, 2018) proses pelaksanaan pembelajaran PPKn di dalam kelas cenderung membosankan bagi siswa sekolah dasar yang menyebabkan rendahnya kompetensi pengetahuan PPKn. Menurut Lestari (2017) Maka dari itu guru dapat merancang sebuah pembelajaran yang dapat mengaktifkan peserta didik. Guru juga harus mampu mengelola pembelajaran guna menciptakan kegiatan pembelajaran yang menyenangkan. Menurut Rahayuni (2018) Pelajaran PPKn sebaiknya tidak hanya mengutamakan penjelasan dari guru dan materi yang ada dalam buku, tetapi mampu memahami dengan konsepnya sendiri. Pembelajaran PPKn diharapkan mampu meningkatan rasa cinta tanah air bagi peserta didik (N. P. A. Rahayuni , 2018) 
Berdasarkan permasalahan yang terjadi, maka guru diminta untuk mampu merancang kegiatan belajar mengajar yang mampu meningkatkan kompetensi pengetahuan siswa. Menurut Artawan \& Ardiawan (2018) Pembelajaran akan bermakna apabila setiap proses pembelajaran melibatkan dua pelaku aktif yaitu guru dan siswa. Model pembelajaran yang dipilih melibatkan partisipasi aktif siswa. Menurut Joyce, dkk. (2016) Model pembelajaran diartikan sebagai suatu usaha membangun asuhan dan ekosistem dimana di dalamnya peserta didik belajar dengan berinteraksi dan berhubungan dengan komponen-komponennya. Belajar melalui model memiliki peran untuk membantu siswa dalam menemukan jati diri di dalam lingkungan sekolah dan memecahkan permasalahan dengan bantuan dari kelompok belajarnya. Adapun model pembelajaran kooperatif memerlukan peran dan partisipasi aktif dan kreatif dari masing-masing anggota kelompok. Model pembelajaran Round Club dikatakan sebagai salah satu model pembelajaran kooperatif yang cocok diterapkan untuk meningkatkan dan menumbuhkan keaktifan siswa dan kerjasama kelompok siswa dalam peaksanaan pembelajaran di kelas.

Menurut Kurniasih \& Sani (2015) model pembelajaran Round Club adalah suatu proses belajar mengajar menggunakan penerapan dengan berkelompok agar adanya rasa kerjasama antar siswa dan dapat saling bantumembantu dalam mengkonstruksi konsep. Model Round Club diartikan agar setiap anggota kelompok mendapat serta hasil diskusi anggota lain. Menurut Istarani (2015) keunggulan model pembelajaran Round Club antara lain : (1) Mampu membuat peserta didik untuk menyampaikan semua pendapatnya saat kegiatan diskusi di dalam kelompok (2) Mampu meningkatkan rasa peserta didik untuk mendengarkan temannya dan menerima masukkan orang lain dengan baik, (3) Mampu menciptakan rasa saling membantu antar peserta didik, karena bisa saja akan ada perbedaan pendapat antar kelompok (4) Mampu melatih dan meningkatkan rasa percaya diri siswa dalam menyampaikan pendapat, (5) Mampu menambah kemampuan menyampaikan pendapatnya dengan baik, benar dan sopan.

Karakteristik dalam model ini adalah setiap kelompok diajarkan untuk bertanggung jawab, baik dalam berpikir yang baik secara individu, berdiskusi dengan baik dalam kelompok dan diakhiri dengan membuat hasil kelompok berupa laporan atau presentasi dengan membagikan gagasan hasil diskusi mereka dengan teman-teman yang lain didalam kelas. Sesuai dengan pernyataan tersebut model Round $C l u b$ sejalan dengan ajaran agama yaitu konsep Tri Kaya Parisudha. Selain penggunaan suatu model pembelajaran yang tepat, untuk menumbuhkan rasa kesadaran, moral karakter pada siswa saat pembelajaran maka perlu suatu pengembangan inovasi baru dalam pelaksanaan pembelajaran PPKn yaitu model pembelajaran yang berbasis Tri Kaya Parisudha. (Selamet et al., 2017)

Menurut Suhardana (2007) Tri Kaya Parisudha merupakan ajaran agama hindu yang perlu diterapkan. Tri Kaya Parisudha terdiri atas kata Tri, Kaya dan Parisudha yang artinya tiga perilaku baik. Maka dari itu Tri Kaya Parisudha diartikan sebagai 3 sifat manusia dalam berpikir, berucap dan berperilaku yang perlu disucikan. Menurut Suarnaya (2015) Tri Kaya Parisudha adalah pembelajaran tentang cara memiliki perilaku baik, dari adanya pikiran yang baik dan benar, maka dapat menimbulkan perkataan yang baik pula, dan pada akhirnya akan mengarah pada perbuatan yang baik pula. Tri Kaya Parisudha dijadikan dasar untuk mendorong anak agar mampu berperilaku yang baik sesuai dengan perkembangannya (Indrayani et al., 2014) . Menurut Suarjana (2018) Apabila dikaitkan dengan pembelajaran PPKn, maka konsep Tri Kaya Parisudha mengarah pada pembentukan nilai, moral dan sikap yang baik.Menurut Paryanata (2019) Dengan berlandaskan ajaran Tri Kaya Parisudha sebagai dasar kita dalam bersikap dan dipadukan dengan model pembelajaran Round Club yang mengarahkan siswa mampu berperan secara aktif dalam pembelajaran serta mampu mempunyai rasa tanggung jawab dan kerjasama lebih baik. Menurut Arsani (2013) model pembelajaran Round Club berbasis Tri Kaya Parisudha memiliki kelebihan yaitu model Round Club membantu siswa untuk bertanggung jawab dan siswa mampu saling mendengarkan dan mengutarakan tanggapan dari setiap anggota kelompok, sehingga mampu meningkatkan pengetahuan kelompok tersebut (Kurniasih,2017). Selama kegiatan pembelajaran siswa dapat lebih aktif karena model pembelajaran Round Club berbasis Tri Kaya Parisudha menciptakan lingkungan belajar yang membuat semua siswa aktif berpartisipasi dalam pembelajaran dikelas (Sumiati, 2015)

Berdasarkan atas keunggulan model pembelajaran Round Club berbasis Tri Kaya Parisudha, dapat mengoptimalkan pembelajaran PPKn. Pernyataan ini didukung oleh dua peneliti, menurut Fitri \& Yani (2017)"model pembelajaran round club digunakan untuk mencari adanya pengaruh terhadap kemampuan komunikasi siswa". Ini dibuktikan dengan $t_{\text {hitung }}>t_{\text {tabel }}$ diperoleh rentangan hasil kemampuan komunikasi siswa eksperimen lebih tinggi dari siswa kelompok kontrol yaitu 2,255 > 
2,0003. Kemudian menurut Wahyuni (2017) "pembelajaran berbasis Tri Kaya Parisudha dalam proses belajar mengajar dapat mendorong siswa untuk berpikir, berbicara dan bertingkah laku dengan baik yang berpengaruh terhadap kompetensi pengetahuan siswa". Hal ini dibuktikan dengan $t_{\text {hitung }}>t_{\text {tabel }}$ diperoleh penguasaan kompetensi dari pengetahuan peserta didik kelompok eksperimen lebih tinggi daripada kontrol yaitu 5,40 > 2,00.

Dari penjelasan tersebut, sehingga penelitian ini bertujuan untuk menganalisis apakah terdapat pengaruh model pembelajaran Round Club berbasis Tri Kaya Parisudha terhadap kompetensi pengetahuan PPKn siswa kelas IV SDN Gugus III Kecamatan Tampaksiring Tahun Ajaran 2019/2020.

\section{METODE}

Penelitian ini merupakan penelitian kuantitatif dengan desain penelitiannya yaitu desain eksperimen semu (quasi experiment) dengan rancangan Non-equivalent control group design. Populasi dari penelitian ini yakni seluruh siswa IV SDN Gugus III Kecamatan Tampaksiring Tahun Ajaran 2019/2020 yang teridiri dari lima sekolah dasar negeri. Adapun jumlah dari populasi yang menjadi penelitian ini adalah 149 siswa. Teknik yang digunakan untuk menentukan sampel adalah teknik Random Sampling. Pemilihan sampel secara acak atau random sampling dilakukan melalui system undian yang dilakukan sebanyak dua kali. Pengundian pertama diperoleh 2 kelas sebagai sampel penelitian yaitu SD Negeri 2 Sanding dan SD Negeri 1 Pejeng Kaja. Kedua kelas tersebut diundi kembali untuk menentukan kelas eksperimen dan kelas kontrol. Dari hasil random yang dilakukan, SD yang terpilih adalah siswa kelas IV SD Negeri 2 Sanding yang berjumlah 33 orang sebagai kelompok eksperimen dan siswa kelas IV SD Negeri 1 Pejeng Kaja yang berjumlah 31 orang sebagai kelompok kontrol. Jumlah sampel keseluruhan adalah 64 orang.

Metode yang digunakan untuk mengumpulkan data pada penelitian ini adalah metode tes dan instrumen yang digunakan dalam adalah tes pilihan ganda. Instrumen ini digunakan untuk mengukur kompetensi pengetahuan PPKn siswa pada dua kelas yang diberikan perlakuan yang berbeda, yaitu kelas eksperimen dan kelas kontrol. Data dalam penelitian ini diperoleh pada akhir penelitian dengan memberikan post-test kepada subyek dalam penelitia ini. Tes kompetensi pengetahuan PPKn yag digunakan adalah tes objektif dalam bentuk pilihan ganda berjumlah 32 soal. Tes pilihan ganda biasa menyediakan alternatif jawaban a, b, c dan d yang apabila siswa menjawab benar butir tes mendapat skor 1 dan skor 0 apabila siswa menjawab salah. Tes pilihan ganda disusun sesuai kisi-kisi soal yang memuat KD dan indikator. Berikut ini disajikan kisi-kisi tes kompetensi pengetahuan PPKn kelas IV.

Tabel 1. Kisi-Kisi Instrumen Pengumpulan Data Kompetensi Pengetahuan PPKn

\begin{tabular}{|c|c|c|}
\hline Kompetensi Dasar & Indikator Soal & $\begin{array}{l}\text { Ranah } \\
\text { Kognitif }\end{array}$ \\
\hline \multirow{6}{*}{$\begin{array}{l}\text { 3.3 Menjelaskan manfaat } \\
\text { keberagaman } \\
\text { karakteristik individu } \\
\text { dalam kehidupan } \\
\text { sehari-hari. }\end{array}$} & $\begin{array}{l}\text { 3.3.1 Menyebutkan manfaat cita-cita } \\
\text { keberagaman karakteristik individu dalam } \\
\text { kehidupan sehari-hari. }\end{array}$ & $\mathrm{C} 1$ \\
\hline & $\begin{array}{l}\text { 3.3.2 Mengidentifikasi keragaman kegiatan } \\
\text { dalam masyarakat. }\end{array}$ & $\mathrm{C} 4$ \\
\hline & $\begin{array}{l}\text { 3.3.3 Menentukan perilaku dalam } \\
\text { keberagaman karakteristik individu di } \\
\text { kehidupan sehari-hari. }\end{array}$ & $\mathrm{C} 3$ \\
\hline & $\begin{array}{l}\text { 3.3.4 Membedakan keberagaman rumah } \\
\text { adat dan makanan daerah sebagai } \\
\text { identitas bangsa Indonesia }\end{array}$ & $\mathrm{C} 2$ \\
\hline & $\begin{array}{l}\text { 3.3.5 Menyebutkan keberagaman agama } \\
\text { dalam kehidupan bernegara. }\end{array}$ & C1 \\
\hline & $\begin{array}{l}\text { 3.3.6 Mengklasifikasikan keberagaman } \\
\text { tempat ibadah di Indonesia. }\end{array}$ & $\mathrm{C} 2$ \\
\hline
\end{tabular}




\begin{tabular}{lll}
\hline Kompetensi Dasar & \multicolumn{1}{c}{ Indikator Soal } & \multicolumn{1}{c}{$\begin{array}{c}\text { Ranah } \\
\text { Kognitif }\end{array}$} \\
\hline & $\begin{array}{l}\text { 3.3.7 Menganalisis akibat perilaku } \\
\text { toleransi dalam keberagaman di } \\
\text { kehidupan sehari-hari. }\end{array}$ & $\mathrm{C} 4$ \\
\hline
\end{tabular}

Tes ini diberikan kepada siswa pada akhir pembelajaran (post-test). Tes yang digunakan sudah melalui proses uji coba yaitu, uji validitas, uji daya beda, uji tingkat kesukaran dan uji reliabilitas. Analisis data dalam penelitian ini menggunakan analisis statistic inferensial. Untuk menganalisis data guna menguji hipotesis penelitian, digunakan uji t. Seblum dianalisis terlebih dahulu dilakukan uji prasyarat analisis yang meliputi uji normalitas sebaran data dan uji homogenitas varians.

\section{HASIL DAN PEMBAHASAN}

Berdasarkan tujuan penelitian maka pelaksanaan pnelitian dilakukan kepada sampel penelitian yakni kelompok eksperimen kelas IV SD Negeri 2 Sanding dan kelas IV SD Negeri 1 Pejeng Kaja menjadi kelas kontrol. Setiap kelas diberikan 6 kali perlakuan dan selanjutnya diberikan post-test guna mendapatkan skor dari setiap sampelnya. Berdasarkan perhitungan yang dilakukan dapat dideskripsikan data kedua kelompok penelitian sebagai berikut.

Tabel 2.Deskripsi data Kompetensi Pengetahuan PPKn

\begin{tabular}{ccc}
\hline Deskripsi Data & Kelompok Eksperimen & Kelompok Kontrol \\
\hline $\mathrm{N}$ & 33 & 31 \\
\hline Mean & 86,76 & 80,16 \\
\hline Standar Deviasi & 8,15 & 8,06 \\
\hline Varians & 66,44 & 65,01 \\
\hline
\end{tabular}

Berdasarkan Tabel 2. Didapatkan nilai mean kelompok eksperimen yakni 86,76 dan pada kelompok kontol yakni 80,16. Hal ini berarti nilai rerata yang dimiliki kelompok eksperimen lebih tinggi dari kelompok kontrol. Selanjutnya sesuai hasil post-test disusun tabel distribusi frekuensi relatif kelompok penelitian.

Tabel 3. Tabel Distribusi Frekuensi Relatif Kompetensi Pengetahuan PPKn Kelompok Eksperimen

\begin{tabular}{ccc}
\hline $\mathbf{X}$ & $\mathbf{F}$ & $\boldsymbol{F r} \mathbf{( \% )}$ \\
\hline 69 & 1 & $3 \%$ \\
\hline 72 & 1 & $3 \%$ \\
\hline 75 & 3 & $9 \%$ \\
\hline 78 & 2 & $6 \%$ \\
\hline 81 & 2 & $6 \%$ \\
\hline 84 & 5 & $15 \%$ \\
\hline 88 & 6 & $18 \%$ \\
\hline 91 & 3 & $9 \%$ \\
\hline 94 & 5 & $15 \%$ \\
\hline 97 & 4 & $12 \%$ \\
\hline 100 & 1 & $3 \%$ \\
\hline Jumlah & $\mathbf{3 3}$ & $\mathbf{1 0 0 \%}$ \\
\hline
\end{tabular}

Pada tabel 3, diketahui bahwa siswa pada kelompok eksperimen yang mampu memenuhi nilai KKM 75, sebanyak 94\%. Hanya 6\% siswa belum memenuhi KKM. Hal ini berarti sebagian besar siswa yaitu 94\% dari 100\% siswa sudah mampu memenuhi KKM yang telah ditentukan. Berikut ini disajikan pula tabel distribusi frekuensi relatif kompetensi pengetahuan PPKn pada kelompok kontrol sebagai berikut. 
Tabel 4. Tabel Distribusi Frekuensi Relatif Kompetensi Pengetahuan IPS Kelompok Kontrol

\begin{tabular}{ccc}
\hline $\mathbf{X}$ & $\mathbf{F}$ & $\mathbf{F r} \mathbf{( \% )}$ \\
\hline 66 & 2 & $6 \%$ \\
\hline 69 & 2 & $6 \%$ \\
\hline 72 & 2 & $6 \%$ \\
\hline 75 & 4 & $13 \%$ \\
\hline 78 & 5 & $17 \%$ \\
\hline 81 & 6 & $19 \%$ \\
\hline 84 & 3 & $10 \%$ \\
\hline 88 & 1 & $3 \%$ \\
\hline 91 & 3 & $10 \%$ \\
\hline 94 & 3 & $10 \%$ \\
\hline Jumlah & $\mathbf{3 1}$ & $\mathbf{1 0 0 \%}$ \\
\hline
\end{tabular}

Berdasarkan tabel 4, diketahui bahwa siswa pada kelompok kontrol mampu memenuhi nilai KKM yang ditentukan yaitu 75 sebanyak 82\% dan sebanyak 18\% siswa belum memenuhi KKM. Hal ini berarti sebagian besar siswa yakni 18\% belum mampu memenuhi KKM yang telah ditentukan.

Sebelum uji t dilakukan, maka harus melewati tahapan uji prasyarat yang pertama yakni uji normalitas sebagai berikut.

Tabel 5. Hasil Uji Normalitas antar Kelompok Eksperimen dan Kelompok Kontrol

\begin{tabular}{cccccc} 
No & $\begin{array}{c}\text { Kelompok } \\
\text { sampel }\end{array}$ & $\begin{array}{c}\text { Total } \\
\text { Sampel }\end{array}$ & $\begin{array}{c}\text { Nilai } \\
\text { Maksimum } \\
\left|\mathbf{F}_{\mathrm{T}}-\mathbf{F}_{\mathrm{S}}\right|\end{array}$ & $\begin{array}{c}\text { Nilai KS } \mathbf{S}_{\text {tabel }} \\
\text { Kolmogorov } \\
\text { Smirnov }\end{array}$ & Keterangan \\
\hline 1 & Eksperimen & 33 & 0,11 & 0,23 & Berdistribusi normal \\
\hline 2 & Kontrol & 31 & 0,14 & 0,24 & Berdistribusi normal \\
\hline
\end{tabular}

Berdasarkan hasil analisis uji normalitas pada kelompok eksperimen, diperoleh nilai maksimum $\left|\mathrm{F}_{\mathrm{T}}-\mathrm{F}_{\mathrm{S}}\right|$ yaitu 0,11 kemudian nilai tersebut dibandingkan dengan $\mathrm{KS}_{\text {tabel }}$ Kolmogorov Smirnov = 0,23. Hal ini menunjukkan bahwa nilai maksimum $\left|\mathrm{F}_{\mathrm{T}}-\mathrm{F}_{\mathrm{S}}\right|<\mathrm{KS}_{\text {tabel }}$ Kolmogorov Smirnov dapat diartikan data pada hasil kompetensi pengetahuan PPKn kelompok eksperimen dikatakan berdistribusi normal. Hasil analisis uji normalitas pada kelompok kontrol, diperoleh nilai maksimum $\left|\mathrm{F}_{\mathrm{T}}-\mathrm{F}_{\mathrm{S}}\right|$ yaitu 0,14 kemudian nilai tersebut dibandingkan dengan $\mathrm{KS}_{\text {tabel }}$ Kolmogorov Smirnov $=0,24$. Hal ini menunjukkan bahwa nilai maksimum $\left|\mathrm{F}_{\mathrm{T}}-\mathrm{F}_{\mathrm{S}}\right|<\mathrm{KS}_{\text {tabel }}$ Kolmogorov Smirnov dapat diartikan data hasil Kompetensi Pengetahuan PPKn kelompok kontrol berdistribusi normal.

Tabel 6. Hasil Uji Homogenitas Varians antar Kelompok Eksperimen dan Kelompok Kontrol

\begin{tabular}{|c|c|c|c|c|c|c|c|}
\hline No & Kelompok & $S_{1}{ }^{2}$ & $S_{2}{ }^{2}$ & $\mathbf{d k}$ & $\mathbf{F}_{\text {hitung }}$ & $\mathbf{F}_{\text {tabel }}$ & Keterangan \\
\hline 1 & Eksperimen & 66,44 & & 32 & \multirow{2}{*}{1,02} & \multirow{2}{*}{1,84} & \multirow{2}{*}{ Homogen } \\
\hline 2 & Kontrol & & 65,01 & 30 & & & \\
\hline
\end{tabular}

Uji homogenitas varians ini dilaksanakan berdasarkan data kompetensi pengetahuan PPKn kelompok eksperimen dan kelompok kontrol. Uji homogenitas dilaksanakan agar mengetahui mengenai adanya perbedaan yang dapat terjadi dalam uji hipotesis memang benar bisa terjadi diakibatkan karena ada beda varians diantara kelompok, bukan sebagai akibat perbedaan dalam kelompok. Uji homogenitas varians dalam penelitian ini mempergunakan uji F. Varians terbesar yaitu 66,44 dibagi varians terkecil 65,01 sehingga mendapatkan hasil 1,021. Dari hasil analisis, diperoleh $F_{\text {hitung }}=1,02$, hasil ini kemudian dibandingkan dengan harga $F_{\text {tabel }}$ pada derajat kebebasan (dk) untuk pembilang n1-1 (33-1=32) dan derajat kebebasan $(\mathrm{dk})$ untuk penyebut $\mathrm{n} 2-1(31-1=30)$ diperoleh $\mathrm{F}_{\text {tabel }}=1,82$. Berdasarkan analisis, 
diperoleh $\mathrm{F}_{\text {hitung }}=1,02$. Hal ini berarti $\mathrm{F}_{\text {hitung }}=1,02<\mathrm{F}_{\text {tabel }}=1,82$ sehingga data kedua kelompok memiliki varians yang homogen.

Hipotesis diuji adalah $\mathrm{H}_{0}$ yaitu tidak ada perbedaan signifikan Tidak terdapat perbedaan yang signifikan Kompetensi Pengetahuan PPKn antara kelompok yang dibelajarkan dengan model pembelajaran Round Club berbasis Tri Kaya Parisudha dengan kelompok yang dibelajarkan melalui pembelajaran konvensional pada kelas IV SDN Gugus III Kecamatan Tampaksiring Tahun Ajaran 2019/2020. Sesuai hasil uji normalitas serta homogenitas varians diperoleh data kelompok eksperimen serta kelompok kontrol berdistribusi normal serta homogen. Sesuai penjelasan sebelumnya sehingga uji statistik yaitu uji-t menggunakan polled varians. Dengan kriteria apabila $\mathbf{t}_{\text {hitung }} \leq \mathbf{t}_{\text {tabel, }}$, artinya $\mathrm{H}_{\mathrm{o}}$ diterima dan $\mathrm{H}_{\mathrm{a}}$ ditolak, dan apabila $\mathrm{t}_{\text {hitung }}>\mathrm{t}_{\text {tabel }}$ artinya $\mathrm{H}_{\mathrm{o}}$ ditolak dan $\mathrm{H}_{\mathrm{a}}$ diterima. Pada taraf signifikan $5 \%$ dengan $\mathrm{dk}=\mathrm{n}_{1}+\mathrm{n}_{2}-2$. Rekapitulasi hasil analisis uji t data post-test sebagai berikut.

Tabel 7. Hasil Analisis Uji-t Data Post-test

\begin{tabular}{|c|c|c|c|c|c|c|c|c|}
\hline No & Sampel & $\begin{array}{l}\text { Rata- } \\
\text { rata }\end{array}$ & Varians & Dk & $\mathbf{N}$ & $\mathbf{t}_{\text {hitung }}$ & $t_{\text {tabel }}$ & Kesimpulan \\
\hline 1 & Kelas & 86,76 & 66,44 & 62 & 33 & 3,267 & 2,000 & Ho ditolak \\
\hline
\end{tabular}

Berdasarkan hasil uji hipotesis dari kompetensi pengetahuan PPKn kelompok eksperimen dan kelompok kontrol diperoleh $t_{\text {hitung }}=3,267$ dalam taraf signifikansi $5 \%$ dengan $\mathrm{dk}=\mathrm{n} 1+\mathrm{n} 2-2=33+31$ $-2=62$ menunjukkan nilai $t_{\text {tabel }}=2,000$ sehingga $t_{\text {hitung }}>t_{\text {tabel }}(3,267>2,000) . H_{0}$ yang berbunyi tidak terdapat perbedaan yang signifikan Kompetensi Pengetahuan PPKn antara kelompok yang dibelajarkan dengan model pembelajaran Round Club Berbasis Tri Kaya Parisudha dengan kelompok yang dibelajarkan melalui pembelajaran konvensional pada kelas IV SDN Gugus III Kecamatan Tampaksiring Tahun Ajaran 2019/2020 ditolak. Uji hipotesis menunjukkan bahwa terdapat perbedaan yang signifikan kompetensi pengetahuan PPKn antara kelompok siswa yang dibelajarkan menggunakan model pembelajaran Round Club Berbasis Tri Kaya Parisudha dengan kelompok yang dibelajarkan melalui pembelajaran konvensional.

Pemerolehan perhitungan data yang dilaksanakan menunjukkan bahwa nilai rerata kompetensi pengetahuan PPKn kelompok eksperimen yakni 86,76 dan kelompok kontrol yakni 80,16. Hal ini membuktikan bahwa rata-rata dari kompetensi pengetahuan PPKn kelompok eksperimen ini lebih tinggi dibandingkan dengan nilai rata-rata dari kompetensi pengetahuan PPKn dalam kelompok kontrol. Hal ini artinya model pembelajaran Round Club berbasis Tri Kaya Parisudha berpengaruh terhadap kompetensi pengetahuan PPKn siswa. Kedua sampel penelitian memiliki hasil berbeda karena pembelajaran dengan model Round Club berbasis Tri Kaya Parisudha mampu meningkatkan keaktifan siswa saat pembelajaran berlangsung.

Dalam kelompok eksperimen yang diberikan perlakuan melalui model pembelajaran Round Club berbasis Tri Kaya Parisudha dalam kompetensi pengetahuan PPKn berjalan dengan kondusif dan optimal. Berbeda dengan kelompok kontrol yang dibelajarkan menggunakan pembelajaran konvensional. Pembelajaran konvensional secara umum yang dilakukan cenderung hanya disampaikan oleh guru yang membuat siswa merasa bosan. Oleh karena itu model Round Club berbasis Tri Kaya Parisudha merupakan solusi permasalahan saat pembelajaran. Model pembelajaran Round Club memiliki keunggulan diantaranya adalah mampu menyempatkan peserta didik menyampaikan pandangan ketika berlangsungnya diskusi dalam kelompok, mampu membuat peserta didik bisa mendengar pemikiran dari orang lain dengan baik, menciptakan kerjasama antar siswa apabila terdapat perbedaan pendapat (Istarani, 58 C.E.). Penerapan model Round Club belum sempurna tanpa berlandaskan ajaran kebaikan Tri Kaya Parisudha. Hal ini disebabkan karena model pembelajaran Round Club berbasis Tri Kaya Parisudha memiliki kelebihan yaitu model Round Club membantu siswa untuk bertanggung jawab dan siswa mampu saling mendengarkan dan mengutarakan tanggapan dari setiap anggota kelompok, sehingga mampu meningkatkan pengetahuan kelompok tersebut (Kurniasih,2017). Menurut Wati \& Supriyadi (2017) Model pembelajaran Round Club memberikan kesempatan untuk siswa menyampaikan pendapat mereka kepada kelompok lainnya dalam 
memcahkan masalah. Pembelajaran menggunakan model round club dikatakan sebagai cara efektif untuk mampu menciptakan kegiatan berdiskusi dalam kelas agar mampu berperan secara aktif. Menurut Setiawan (2017) proses pembelajaran menggunakan model round club mempunyai tujuan yakni untuk mengingat dan memotivasi siswa dalam belajar (Fahlevi \& Rosyid, n.d.) Selama kegiatan pembelajaran siswa dapat lebih aktif karena model pembelajaran Round Club berbasis Tri Kaya Parisudha menciptakan lingkungan belajar yang membuat semua siswa aktif berpartisipasi dalam pembelajaran dikelas. Pembelajaran Tri Kaya Parisudha mampu membentuk siswa yang mampu berpikir, berbicara dan bertindak dengan baik (Adnyana \& Citrawathi, 2017). Berbeda dengan kelompok kontrol yang diberikan perlakuan melalui pembelajaran konvensional atau pembelajaran yang biasa dilaksanakan oleh wali kelas. Maka kompetensi pengetahuan PPKn siswa dapat meningkat, PPKn sangat penting diajarkan disekolah dasar agar siswa mampu memiliki rasa cinta terhadap tanah air (Wiyasa, 2018). Pembelajaran dengan model Round Club berbasis Tri Kaya Parisudha sangat tepat diterapkan, karena mampu meningkatkan rasa tanggung jawab serta kekompakkan siswa dalam menyelesaikan suatu permasalahan pada saat diskusi kelompok dengan pikiran, perkataan dan tindakan yang baik.

Adapun implikasi yang didapatkan dalam penemuan-penemuan tersebut menunjukkan bahwa model pembelajaran Round Club berbasis Tri Kaya Parisudha berpengaruh pada kompetensi pengetahuan PPKn siswa Dengan demikian penelitian ini membuktikan bahwa model pembelajaran Round Club berbasis Tri Kaya Parisudha baik diterapkan pada saat pembelajaran salah satunya muatan pelajaran PPKn karena siswa menjadi aktif pada saat pembelajaran berangsung dan membuat proses pembelajaran menjadi menyenangkan dan siswa dapat memahami materi yang dipelajari. Selain itu penerapan model ini dapat meningkatkan interaksi siswa lebih baik karena siswa melakukan kegiatan diskusi kelompok, sehingga pembelajaran akan menjadi menyenangkan bagi siswa dalam melewati proses pembelajaran dan tentu siswa mampu memahami materi yang dipelajari lebih lama.

\section{SIMPULAN DAN SARAN}

Sesuai dengan hasil analisis data post-test menunjukkan bahwa thitung lebih besar dari ttabel dengan nilai rerata kelompok eksperimen lebih tinggi dari kelompok kontrol. Sehingga dapat disimpulkan bahwa model pembelajaran Round Club berbasis Tri Kaya Parisudha berpengaruh terhadap kompetensi pengetahuan PPKn pada siswa kelas IV SDN Gugus III Kecamatan Tampaksiring Tahun Ajaran 2019/2020. Adapun beberapa saran yang dapat diajukan sebagai tindak lanjut dari penelitian ini untuk guqru, kepala sekolah dan peneliti lainnya diharapkan agar selalu mendukung penggunaan model pembelajaran yang inovatif, sehingga siswa lebih aktif dalam proses pembelajaran; sehingga siswa mampu memperoleh pengalaman belajar yang lebih bermakna, dijadikan pedoman bagi sekolah dan pendukung sumber belajar bagi guru sehingga dapat menciptakan kualitas pembelajaran di sekolah dasar, serta agar dijadikan referensi untuk melaksanakan penelitian selanjutnya atau menemukan inovasi kegiatan pembelajaran yang bermakna bagi siswa.

\section{DAFTAR PUSTAKA}

Adnyana, P. B., \& Citrawathi, D. M. (2017). Model Pendidikan Karakter Berbasis Tri Kaya Parisudha Terintegrasi Dalam Pembelajaran Di Sekolah Dasar. Seminar Nasional Riset Inovatif, 5, 862-868.

Arsani, N. N. S., Murda, I. N., \& Wirya, I. N. (2013). Pengaruh Metode Pembelajaran Bermain Peran Berorientasi Kearifan Lokal Tri Kaya Parisudha Terhadap Hasil Belajar Pendidikan Kewarganegaraan Siswa Kelas V Sd. MIMBAR PGSD Undiksha, 1(1).

Artawan, K. N., \& Ardiawan, I. K. N. (2018). Pembelajaranquantum Teachingberbasis Tri Kaya Parisudha. Edudikara: Jurnal Pendidikan Dan Pembelajaran, 3(2), 201-212.

Astiti, N. K. A., Suarjana, I. M., \& Arini, N. W. (2017). Pengaruh Model Pembelajaran Vct Berbantuan Power Point Terhadap Hasil Belajar Pkn Kelas V. MIMBAR PGSD Undiksha, 5(2).

Bachtiar, M. Y. Y. E., Zulfahmi, I. F., \& Indriani, D. (2019). Model Pembelajaran Round Club Dan Model Pembelajaran Jigsaw Terhadap Hasil Belajar PPKn Peserta Didik Sekolah Dasar. Jurnal Pendidikan Dasar, 10(1), 132-143.

Darmadi, H. (2015). Pendidikan Kewarganegaraan sebagai Sarana Membangun Karakter Bangsa. Tersedia Secara Online Di: Https://Dcc. Ac. Id/Galeri_dok/Upload/809_3-\% 20Pancasila [Diakses Di Kota Malang, Jawa Timur, Indonesia: 27 Juli 2018].

Daryanto, D. (2014). Pendekatan pembelajaran saintifik Kurikulum 2013. Yogyakarta: Gava Media.

Dharma, I. P. W., Kusmariyatni, N., \& Sudana, D. N. (2018). Pengaruh Model Numbered Head Together 
Berbasis Tri Kaya Parisudha Terhadap Kompetensi Pengetahuan IPS Siswa Kelas IV SD. Jurnal Pendidikan IPS Indonesia, 2(2), 75-85.

Fahlevi, Z. M., \& Rosyid, A. (n.d.). Pengaruh Model Pembelajaran Round Club Terhadap Kecerdasan Linguistik Siswa Kelasv Sdn Sukabumi Utara 04 Pagi.

Fitri, R., \& Yani, O. (2017). Penerapan Model Pembelajaran Round Club Terhadap Kemampuan Komunikasi Matematis Siswa. MES: Journal of Mathematics Education and Science, 2(2).

Indrayani, P. S., Arini, N. W., \& Rati, N. W. (2014). Pengaruh model pembelajaran kooperatif tipe TTW berbasis kearifan lokal tri kaya parisudha terhadap hasil belajar IPA pada siswa kelas V SD. MIMBAR PGSD Undiksha, 2(1).

Istarani, I. (58 C.E.). Model Pembelajaran Inovatif. Medan: Media Persada.

Kurniasih, I., \& Sani, B. (2015). Ragam pengembangan model pembelajaran untuk peningkatan profesionalitas guru. Jakarta: Kata Pena, 71-72.

Lestari, N. M. D., Suniasih, N. W., \& Darsana, I. W. (2017). Pengaruh Model Pembelajaran Snowball Throwing Berbasis Lagu-Lagu Anak Terhadap Kompetensi Pengetahuan Pkn. Journal of Education Technology, 1(3), 163-168.

Murni, H. (2018). Upaya Meningkatkan Hasil Belajar Pkn Melalui Model Pembelajaran Kooperatif Tipe Think Pair Share. Wahana Didaktika, 16(3).

Paryanata, I. M. R., Agung, A. A. G., \& Suarjana, I. M. (2019). Pengaruh Model Pembelajaran Think Pair Share Berbasis Tri Kaya Parisudha Terhadap Hasil Belajar Ips. Jurnal Pendidikan Multikultural Indonesia, 2(1), 22-31.

Puspitasari, N. L. P. E., Putra, I. M., \& Putra, I. K. A. (2013). Pengaruh Strategi Pembelajaran Pq4r Dan Motivasi Belajar Terhadap Hasil Belajar Pkn Siswa Kelas Iv Sd Gugus 2 Tampaksiring. MIMBAR PGSD Undiksha, 1(1).

Rahayuni, A. (2018). Pengaruh Model Pembelajaran Pair Check Berbasis Penilaian Kinerja terhadap Kompetensi Pengetahuan PKn. Jurnal Penelitian Dan Pengembangan Pendidikan, 2(1).

Rahayuni, N. P. A., Asri, I. G. A. A. S., \& Suniasih, N. W. (2018). Pengaruh Model Pembelajaran Pair Check Berbasis Penilaian Kinerja Terhadap Kompetensi Pengetahuan Pkn Siswa Kelas Iv. Mimbar Ilmu, 23(1), 65-72.

Selamet, N. W., Tegeh, I. M., \& Dharmayanti, P. A. (2017). Pengaruh Model Pembelajaran Numbered Head Together Berbasis Tri Kaya Parisudha Terhadap Hasil Belajar Ips Siswa Kelas Iv. MIMBAR PGSD Undiksha, 5(2).

Septiari, N. L. P. D., Asri, I. G. A. A. S., \& Suniasih, N. W. (2019). Pengaruh Model Pembelajaran Value Clarification Technique Berbasis Penilaian Proyek Terhadap Kompetensi Pengetahuan PKn. Jurnal Pedagogi Dan Pembelajaran, 1(2), 67-75.

Setiawan, A. S. (2017). Pengaruh Model Pembelajaran Think Talk Write (TTW) dan Model Pembelajaran Round Club terhadap Kemampuan Komunikasi Matematis Siswa. Universitas Muhammadiyah Jember.

Suarjana, I. M., Dibia, I. K., \& Sariani, N. L. A. (2018). Pengaruh Model Pembelajaran CTL Berorientasi Tri Kaya Parisudha terhadap Hasil Belajar Matematika. International Journal of Elementary Education, 2(3), 237-245.

Suarnaya, K. D., Dibia, I. K., \& Suarjana, I. M. (2015). Pengaruh Model Pembelajaran Tandur Berbasis Kearifan Lokal Tri Kaya Parisudha Terhadap Hasil Belajar IPA. MIMBAR PGSD Undiksha, 3(1).

Suhardana, K. M. (2007). Tri Kaya Parisuda Bahan Kajian Untuk Berfikir Baik, Berkata Baik dan Berbuat Baik. Surabaya: Paramita.

Sumiati, S., Syamsi, F., \& Sari, N. P. (2015). Pengaruh Model Pembelajaran Round Club Terhadap Hasil Belajar Siswa Kelas Vii Pada Pokok Bahasan Ekosistem Di Smpn 35 Batam. Simbiosa, 4(1).

Wahyuni, N. K. C., Made Putra, M. P., \& Darsana, I. W. (2017). Pengaruh Model Pembelajaran Think Talk Write Berbasis Tri Kaya Parisudha Terhadap Penguasaan Kompetensi Pengetahuan Ips. MIMBAR PGSD Undiksha, 5(2).

Wati, R. N., \& Supriyadi, A. (2017). Upaya Meningkatkan Hasil Belajar Matematika dengan Menerapkan Model Pembelajaran Round Club berbantuan Media Monopoly Game Smart pada Peserta Didik Kelas VB Di SDN-1 Sabaru Palangka Raya Tahun Pelajaran 2016/2017. Tunas: Jurnal Pendidikan Guru Sekolah Dasar, 3(1), 8-14.

Wiyasa, I. K. N. (2018). Pengaruh Model Pembelajaran Open Ended Berbasis Penilaian Proyek Terhadap Kompetensi Pengetahuan Ppkn Siswa. Jurnal Imiah Pendidikan Dan Pembelajaran, 2(2).

Yuliasari, N. P. S., Agung, A. A. G., \& Suwatra, I. I. W. (2013). Pengaruh Model Pembelajaran VCT 
Jurnal Adat dan Budaya Vol. 2, No. 2, Tahun 2020, pp. 63-72

Berbantuan Media Power Point Terhadap Hasil Belajar PKn Siswa Kelas V SD Gugus V Kecamatan Buleleng. MIMBAR PGSD Undiksha, 1(1). 